\title{
Prevalence and mutation spectrum of skeletal muscle channelopathies in the Netherlands
}

Citation for published version (APA):

Stunnenberg, B. C., Raaphorst, J., Deenen, J. C. W., Links, T. P., Wilde, A. A., Verbove, D. J., Kamsteeg, E. J., van den Wijngaard, A., Faber, C. G., van der Wilt, G. J., van Engelen, B. G. M., Drost, G., \& Ginjaar, $\mathrm{H}$. B. (2018). Prevalence and mutation spectrum of skeletal muscle channelopathies in the Netherlands. Neuromuscular Disorders, 28(5), 402-407. https://doi.org/10.1016/j.nmd.2018.03.006

Document status and date:

Published: 01/05/2018

DOI:

10.1016/j.nmd.2018.03.006

Document Version:

Publisher's PDF, also known as Version of record

Document license:

Taverne

Please check the document version of this publication:

- A submitted manuscript is the version of the article upon submission and before peer-review. There can be important differences between the submitted version and the official published version of record.

People interested in the research are advised to contact the author for the final version of the publication, or visit the DOI to the publisher's website.

- The final author version and the galley proof are versions of the publication after peer review.

- The final published version features the final layout of the paper including the volume, issue and page numbers.

Link to publication

\footnotetext{
General rights rights.

- You may freely distribute the URL identifying the publication in the public portal. please follow below link for the End User Agreement:

www.umlib.nl/taverne-license

Take down policy

If you believe that this document breaches copyright please contact us at:

repository@maastrichtuniversity.nl

providing details and we will investigate your claim.
}

Copyright and moral rights for the publications made accessible in the public portal are retained by the authors and/or other copyright owners and it is a condition of accessing publications that users recognise and abide by the legal requirements associated with these

- Users may download and print one copy of any publication from the public portal for the purpose of private study or research.

- You may not further distribute the material or use it for any profit-making activity or commercial gain

If the publication is distributed under the terms of Article $25 \mathrm{fa}$ of the Dutch Copyright Act, indicated by the "Taverne" license above, 


\title{
Prevalence and mutation spectrum of skeletal muscle channelopathies in the Netherlands
}

\author{
B.C. Stunnenberg a,*, J. Raaphorst ${ }^{\text {a }}$, J.C.W. Deenen ${ }^{a}$, T.P. Links ${ }^{b}$, A.A. Wilde ${ }^{c}$, D.J. Verbove ${ }^{\mathrm{d}}$, \\ E.J. Kamsteeg ${ }^{\mathrm{e}}$, A. van den Wijngaard ${ }^{\mathrm{f}}$, C.G. Faber ${ }^{\mathrm{g}}$, G.J. van der Wilt ${ }^{\text {h}}$, B.G.M. van Engelen ${ }^{\text {a }}$, \\ G. Drost ${ }^{\mathrm{i}}$, H.B. Ginjaar ${ }^{\mathrm{d}}$ \\ ${ }^{a}$ Department of Neurology, Radboud University Medical Center, Nijmegen, The Netherlands \\ ${ }^{\mathrm{b}}$ Department of Endocrinology, University of Groningen, University Medical Center Groningen, Groningen, The Netherlands \\ ${ }^{\circ}$ Heart Centre, Department of Clinical and Experimental Cardiology, Amsterdam Medical Centre, Amsterdam, The Netherlands \\ ${ }^{d}$ Department of Human and Clinical Genetics, Leiden University Medical Centre, Leiden, The Netherlands \\ ${ }^{\mathrm{e}}$ Department of Human Genetics, Radboud University Medical Center, Nijmegen, The Netherlands \\ ${ }^{\mathrm{f}}$ Clinical Genetics, Maastricht University Medical Center, Maastricht, The Netherlands \\ ${ }^{\mathrm{g}}$ Department of Neurology, Maastricht University Medical Center, Maastricht, The Netherlands \\ ${ }^{\mathrm{h}}$ Department of Health Evidence, Radboud University Medical Center, Nijmegen, The Netherlands \\ ${ }^{i}$ Department of Neurology and Neurosurgery, University of Groningen, University Medical Center Groningen, Groningen, The Netherlands
}

Received 19 November 2017; received in revised form 7 February 2018; accepted 5 March 2018

\begin{abstract}
Few reliable data exist on the prevalence of skeletal muscle channelopathies. We determined the minimum point prevalence of geneticallydefined skeletal muscle channelopathies in the Netherlands and report their mutation spectrum. Minimum point prevalence rates were calculated as number of genetically-confirmed skeletal muscle channelopathy patients (CLCN1, SCN4A, CACNA1S and KCNJ2 gene mutations) in the Netherlands (1990-2015) divided by the total number of at-risk individuals. Rates were expressed as cases/100.000 and $95 \%$ confidence intervals were calculated based on Poisson distribution. Results of standardized genetic diagnostic procedures were used to analyze mutation spectra. We identified 405 patients from 234 unrelated pedigrees, resulting in a minimum point prevalence of 2.38/100.000 (95\% CI 2.16-2.63) for skeletal muscle channelopathies in the Netherlands. Minimum point prevalence rates for the disease groups, non-dystrophic myotonia and periodic paralysis, were $1.70 / 100.000$ and $0.69 / 100.000$ respectively.

Sixty-one different CLCN1 mutations (including 12 novel mutations) were detected in myotonia congenita. Twenty-eight different $S C N 4 A$ missense mutations (including three novel mutations) were identified in paramyotonia congenita/sodium channel myotonia, hypokalemic periodic paralysis and hyperkalemic periodic paralysis. Four different $C A C N A 1 S$ missense mutations were detected in hypokalemic periodic paralysis and five KCNJ2 missense mutations in Andersen-Tawil syndrome. The minimum point prevalence rates for genetically-defined skeletal muscle channelopathies confirm their rare disease status in the Netherlands. Rates are almost twice as high as in the UK and more in line with pre-genetic prevalence estimates in parts of Scandinavia. Future diagnostic and therapeutic studies may benefit from knowledge of the mutation spectrum of skeletal muscle channelopathies.
\end{abstract}

(C) 2018 Elsevier B.V. All rights reserved.

Keywords: Skeletal muscle channelopathies; Non-dystrophic myotonia; Periodic paralysis; Prevalence; Netherlands

\footnotetext{
Sponsorship: This study was funded by ZonMw, The Netherlands Organisation for Health Research and Development (ZonMw project number: 152002029).

* Corresponding author. Radboud University Medical Center, Reinier Postlaan 4, 6500HB, Nijmegen, The Netherlands.

E-mail address: Bas.Stunnenberg@radboudumc.nl (B.C. Stunnenberg).
}

\section{Introduction}

Skeletal muscle channelopathies (SMC) form a group of rare, monogenic muscle disorders caused by mutations in genes encoding skeletal muscle ion channels (sodium - SCN4A; chloride - CLCN1; calcium - CACNA1S; potassium - KCNJ2). These mutations disrupt skeletal muscle action potential generation resulting in myotonia, periodic paralyses, or a combination of both $[1,2]$. Different phenotypes are recognized 
within SMC: myotonia congenita (MC, $C L C N 1)$, paramyotonia congenita (PMC, SCN4A) and sodium channel myotonia (SCM, $S C N 4 A$ ) known as the non-dystrophic myotonias (NDM) $[3,4]$. Hypokalemic periodic paralysis (HypoPP, CACNAIS or $S C N 4 A$ ), hyperkalemic periodic paralysis (HyperPP, $S C N 4 A$ ) and Andersen-Tawil Syndrome (ATS, KCNJ2) are known as primary periodic paralyses (PP) $[5,6]$.

There are only few data on the prevalence of SMC in the post-genetic era. A recent nationwide study from the United Kingdom (UK) showed a minimum point prevalence of 1.12/ 100.000 for genetically-defined SMC [7]. Due to founder and geographical effects, prevalence of SMC is believed to vary considerably between countries [7]. Previous genetic studies on SMC in the Netherlands identified the underlying genetic defect in a large HypoPP family, two ATS families, and 54 NDM families $[4,8-10]$. However, until now, no reliable estimate on the prevalence of SMC in the Netherlands has been published. In this study we determine the minimum point prevalence of genetically-defined SMC in the Netherlands and report their mutation spectrum.

\section{Material and methods}

\subsection{Study population}

All patients who received a molecular diagnosis of SMC in the Netherlands from 1990 to 2015 were included in this study. For this, the DNA diagnostic laboratories of the academic medical centers that perform SCN4A,CLCN1, CACNA1S and KCNJ2 mutation analyses (Leiden, Nijmegen, Amsterdam and Maastricht) were contacted. Together, these DNA laboratories serve the entire Dutch population.

\subsection{Data extraction}

From all patients with a genetic diagnosis of SMC, date of birth, gender, affected gene, mutation characteristics, number of first-degree affected family members and hospital of referral were made available to the first author (BCS) by the molecular geneticists of the DNA diagnostic laboratories involved.

No new genetic analyses were performed for this retrospective study. The four genetic centers used standardized genetic diagnostic procedures. The methods for DNA extraction and mutation analysis of the SCN4A, CLCN1 and KCNJ2 genes in patients with SMC have been described in detail elsewhere $[4,11,12]$. In short, the entire coding regions of $S C N 4 A, C L C N 1$ and $K C N J 2$ were sequenced. For CACNA1S, exons 11, 20-21, 26 and 30 have been sequenced. SCN4A and $C L C N 1$ were not sequenced in parallel. No large deletions or duplications were identified in the $C L C N 1$ gene using multiplex ligation-dependent probe amplification (MLPA).

We excluded the possibility that mutation analysis in different members of one family had been performed in distinct laboratories.

In patients who were found to carry only one missense mutation in CLCN1, pedigree and detailed clinical information were retrieved from the treating physician to confirm autosomal dominant MC (i.e. Thomsen's disease). A similar procedure was followed in case of the finding of new mutations.
We calculated minimum point prevalence rates and report mutation spectrum data for both recessive and dominant MC as one group (chloride channelopathies, $\mathrm{ClCh}$ ), and for $\mathrm{PMC} /$ $\mathrm{SCM}$ as one group (sodium channelopathies, $\mathrm{NaCh}$ ).

\subsection{Statistical analysis}

For the different disease subtypes and for the whole cohort of SMC, minimum point prevalence rates were calculated. The prevalence day was January 1, 2015. We used the Dutch Central Bureau of Statistics (Statistics Netherlands, available in English at: https://www.cbs.nl/en-gb) to obtain the number of inhabitants in the Netherlands on the prevalence day $(=16.909 .800)$. The Municipal Personal Database was checked to verify whether our patients were alive on the prevalence day [13]. Minimum point prevalence rates were calculated as the number of genetically confirmed SMC patients in the Netherlands who were alive on the prevalence day, divided by the total number of at-risk individuals (Dutch population). Rates were expressed as cases $/ 100.000$ and $95 \%$ confidence intervals were calculated based on Poisson distribution [14]. Demographic data and mutation spectrum data are presented in means ( \pm standard deviation [SD]) or numbers and percentages. Proportions of genetic referrals among the eight tertiary academic medical centers (and from the group of non-academic centers), and proportions of genetic diagnosis among the four DNA diagnostic laboratories, were assessed. Descriptive statistics were performed using IBM SPSS Statistics 20.

\subsection{Standard protocol approvals, registration, and patient consent}

This study was approved by the Medical Ethical Committee of the Radboud University Medical Center. Since the study concerns only retrospective anonymous genetic and demographic information, informed patient consent was waived.

\section{Results}

\subsection{Minimum point prevalence estimates}

We identified 405 patients from 234 unrelated pedigrees, resulting in a minimum point prevalence of 2.38/100.000 (95\% CI 2.16-2.63) for the whole group of genetically defined SMC in the Netherlands. Minimum point prevalence rates for the disease groups NDM and PP were 1.70/100.000 and 0.69/ 100.000 , respectively (see Table 1).

\subsection{Demographic results and relative distribution of disease categories and subtypes}

On the prevalence day, SMC patients had a mean age of 44 years (SD $\pm 19,19-93)$ and $53 \%$ were female (Table 1). Forty $(10 \%)$ pediatric SMC patients were identified at a mean age of 13 years ( $\mathrm{SD} \pm 5,3-18)$. Almost three quarters of SMC patients (71\%) were diagnosed with NDM and 29\% with PP. Within NDM, $31 \%$ of SMC patients were diagnosed with MC and $40 \%$ with $\mathrm{PMC} / \mathrm{SCM}$. The majority of PP patients was diagnosed with HypoPP (22\%), followed by ATS (4\%) and HyperPP (3\%) (see Fig. 1). Of the 40 pediatric SMC patients, 18 patients were 
Table 1

Demographic characteristics and minimum point prevalence rates of the skeletal muscle channelopathies in the Netherlands.

\begin{tabular}{|c|c|c|c|c|}
\hline & Patients N (pedigrees) & Mean age, years $(\mathrm{SD})^{*}$ & Female $(\%)$ & Prevalence rate $\times 10^{-5}(95 \% \mathrm{CI})$ \\
\hline SMC & 405 (234) & $44( \pm 19)$ & 53 & $2.38(2.16-2.63)$ \\
\hline NDM & $288(188)$ & $43( \pm 20)$ & 52 & $1.70(1.55-1.95)$ \\
\hline $\mathrm{MC}$ & $128(108)$ & $42( \pm 19)$ & 47 & $0.75(0.63-0.90)$ \\
\hline $\mathrm{PMC} / \mathrm{SCM}$ & $160(80)$ & $45( \pm 20)$ & 56 & $0.94(0.81-1.10)$ \\
\hline PP & $117(46)$ & $47( \pm 21)$ & 54 & $0.69(0.57-0.83)$ \\
\hline НуроРР & $90(35)$ & $49( \pm 21)$ & 52 & $0.53(0.43-0.65)$ \\
\hline HyperPP & $10(7)$ & $35( \pm 15)$ & 63 & $0.06(0.03-0.12)$ \\
\hline ATS & $17(6)$ & $40( \pm 20)$ & 59 & $0.10(0.06-0.16)$ \\
\hline
\end{tabular}

Numbers represented the whole disease group of SMC, the two disease categories (NDM and PP) within the SMC, and subtypes within the disease categories (MC, PMC/SCM, HypoPP, HyperPP and ATS).

Abbreviations: $\mathrm{SD}=$ standard deviation; $\mathrm{CI}=$ confidence interval; $\mathrm{SCM}=$ skeletal muscle channelopathies; $\mathrm{PP}=$ primary periodic paralyses; $\mathrm{NDM}=$ non-dystrophic myotonia; $\mathrm{MC}=$ myotonia congenita; $\mathrm{SCM}=$ sodium channel myotonia; $\mathrm{PMC}=$ paramyotonia congenita; $\mathrm{HypoPP}=$ hypokalemic periodic paralysis, HyperPP = hyperkalemic periodic paralysis; ATS = Andersen-Tawil syndrome.

* At time of the prevalence day.

diagnosed with MC, 16 with PMC/SCM, five with HypoPP and one with HyperPP.

\subsection{Mutation spectrum}

Sixty-one different CLCN1 mutations were detected in MC (Table 2), of which the majority represent compound

A
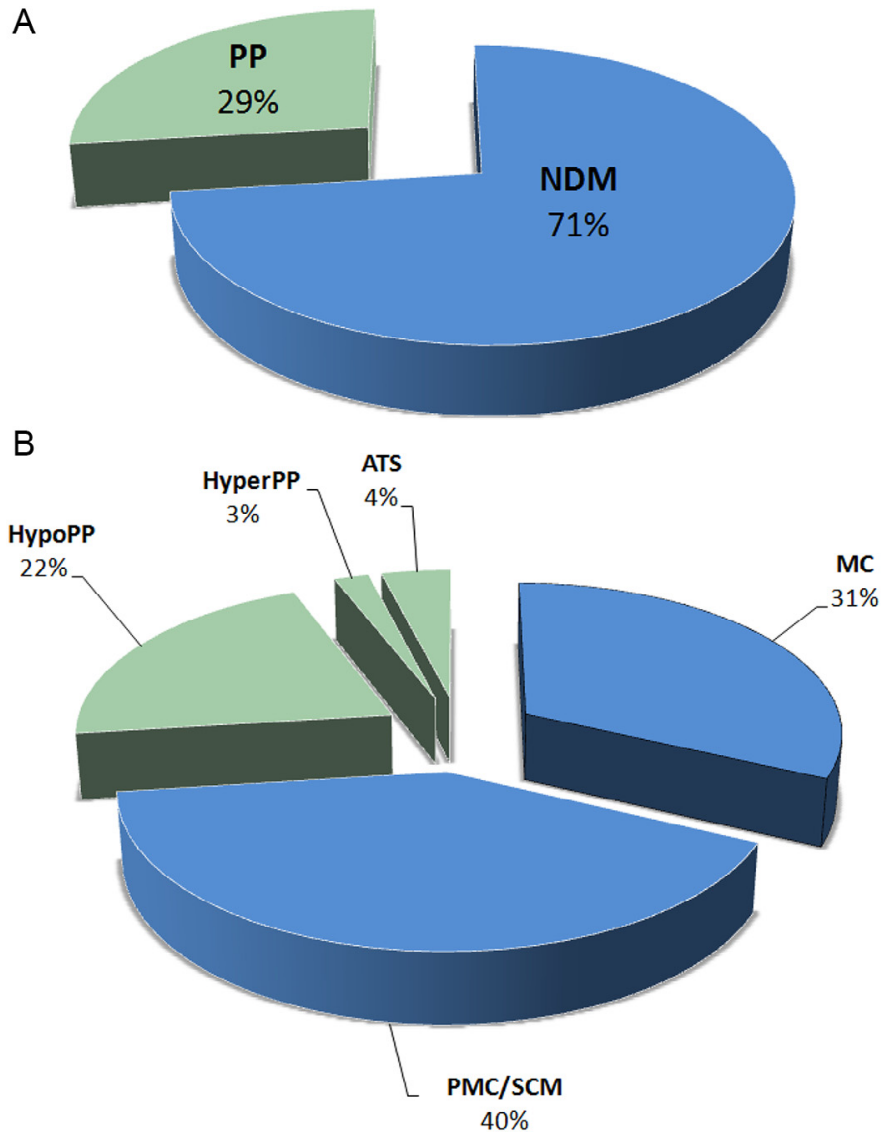

Fig. 1. Circle diagrams of the frequency distributions between the two disease categories (NDM and PP) (A), and all individual disease subtypes (B) within the group of patients with skeletal muscle channelopathies in the Netherlands. Abbreviations: $\mathrm{PP}=$ primary periodic paralyses; $\mathrm{NDM}=$ non-dystrophic myotonia; $\mathrm{MC}=$ myotonia congenita; $\mathrm{SCM}=$ sodium channel myotonia; $\mathrm{PMC}=$ paramyotonia congenita; HypoPP $=$ hypokalemic periodic paralysis, HyperPP = hyperkalemic periodic paralysis; ATS = Andersen-Tawil syndrome. heterozygous or homozygous mutations. Four CLCN1 mutations were found in a heterozygous state only (Ala129Thr, Gly270Val, Val299Leu and Pro480Leu). These mutations were found in a total of nine patients from four different pedigrees with autosomal dominant inheritance (see Fig. S1). Additionally, the Pro480Leu mutation was also detected in two sporadic cases. These four mutations most likely represent dominant $\mathrm{MC}$ mutations since pedigree and clinical information confirmed autosomal dominant inheritance with co-segregation of the mutation and matching myotonic features in at least two generations (Fig. S1). The Pro480Leu and Ala129Thr mutation were previously reported as dominant mutations in CLCN1 [3,4]. Interestingly, the Gly270Val mutation has been reported previously in a homozygous state in a patient from a family with an apparently autosomal dominant inheritance who refused further clinical and genetic investigations of the family [15].

The four most common CLCN1 mutations (Phe167Leu, Gly285Glu, Phe413Cys and Arg894*), of which three were missense mutations and one was nonsense mutation, accounted for $34 \%$ of the mutations. Seventy-six percent of CLCN1 mutations were missense mutations.

Twelve novel CLCN1 mutations were detected in this study: a novel splice site mutation (c. $1401+1 \mathrm{G}>\mathrm{T})$, nonsense mutations (Gly190* and Gln867*), a 6 basepair duplication (Glu808_Gln809dup) and missense mutations (Cys179Trp, Gly255Trp, and Gly523Val). These novel mutations were found as compound heterozygotes in addition to previously reported pathogenic mutations. Novel missense mutations (Gly274Arg and Thr550Ala) were identified in one patient: amino acid Gly at codon 274 is evolutionary highly conserved; at codon 550 a pathogenic missense mutation has been described before (Thr550Met) [16]. Novel frameshift mutation (Phe404Hisfs*16) was found alongside a novel missense mutation (Gly411Cys); amino acid Gly at this codon is evolutionary highly conserved. And novel missense mutation (Leu368Pro) cosegregated homozygously with the disease in the family.

Only missense mutations were responsible for the dominantly inherited sodium, calcium and potassium channelopathies within SMC. Twenty-one different SCN4A 
Table 2

Frequency of individual mutations with chloride channelopathies within the group of patients with skeletal muscle channelopathies in the Netherlands.

\begin{tabular}{|c|c|c|c|}
\hline CLCN1 mutation & MC patients, $\mathrm{N}$ & CLCN1 mutation & MC patients, $\mathrm{N}$ \\
\hline c. $180+3 \mathrm{~A}>\mathrm{T}$ (splice-site $)$ & 4 & Arg317Gln & 2 \\
\hline c.302-2A > C (splice-site) & 6 & Arg338Gln & 1 \\
\hline c.302-1G > A (splice-site) & 7 & Gly355Arg & 1 \\
\hline c. $774+1 \mathrm{G}>\mathrm{A}$ (splice-site $)$ & 3 & Leu368Pro & 4 \\
\hline c. $1065-2 \mathrm{~A}>$ G (splice-site) & 1 & $\operatorname{Arg} 377^{*}$ & 2 \\
\hline c. $1167-10 \mathrm{~T}>\mathrm{C}$ (splice-site) & 8 & Phe404Hisfs*16 & 1 \\
\hline c. 1401 + 1G > T (splice-site) & 1 & Gly411Cys & 1 \\
\hline c. 1471 + 1G > A (splice-site) & 2 & Phe413Cys & 24 \\
\hline Arg105Cys & 2 & Glu417Gly & 1 \\
\hline Tyr137* & 1 & Arg421Cys & 2 \\
\hline Ala129Thr & 4 & Arg421Profs*9 & 1 \\
\hline 1Phe167Leu & 11 & Ile479fs* & 1 \\
\hline Cys179Trp & 2 & Pro480Hisfs $* 24$ & 3 \\
\hline Gly190Ser & 2 & Pro480Leu & 3 \\
\hline Gly190His & 2 & Gly482Arg & 1 \\
\hline Gly190* & 1 & Met485Val & 2 \\
\hline Gly190Arg & 2 & Ala493Glu & 1 \\
\hline Gly233Ser & 3 & Arg496Ser & 1 \\
\hline Lys195Asnfs*62 & 2 & Gly523Val & 1 \\
\hline Gly255Trp & 1 & Glu548Lys & 2 \\
\hline Glu258Glu & 5 & Thr550Ala & 1 \\
\hline Ser264Leufs*4 & 3 & Thr550Met & 2 \\
\hline Thr268Met & 1 & Lys614Met & 1 \\
\hline Gly270Val & 2 & Lys614Asn & 2 \\
\hline Gly274Arg & 1 & Met646Ile & 4 \\
\hline Gly285Glu & 26 & $\mathrm{G} \ln 807^{*}$ & 1 \\
\hline Val299Leu & 2 & Glu808_GIn809dup & 5 \\
\hline Arg300Gln & 1 & Cys819* & 1 \\
\hline $\operatorname{Trp} 303 *$ & 2 & Gln867* & 1 \\
\hline Gly305Glu & 2 & $\operatorname{Arg} 894 *$ & 22 \\
\hline Ala313Thr & 8 & & \\
\hline
\end{tabular}

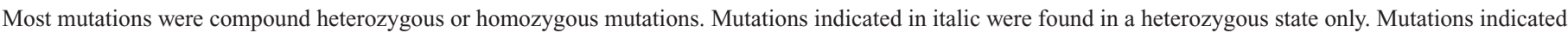
in bold are novel.

Abbreviations: $\mathrm{MC}=$ myotonia congenita; $C L C N 1=$ voltage-gated skeletal muscle chloride channel gene; $\mathrm{N}=$ number.

* Mutation nomenclature is according to HGVS nomenclature version 15.11 (available at: http://varnomen.hgvs.org).

missense mutations were detected in PMC and SCM (Table 3); three different mutations at codon 1306 (Gly1306Ala, Gly1306Glu and Gly1306Val) accounted for $33 \%$ of the $S C N 4 A$ mutations in PMC and SCM. In HypoPP all seven identified mutations (in both $S C N 4 A$ and CACNA1S) were arginine-to-histidine, arginine-to-glutamine or arginine-toglycine substitutions. The Arg528His mutation in CACNA1S accounted for $62 \%$ of the HypoPP patients. Three different missense mutations in SCN4A were responsible for all HyperPP patients, and five different mutations in KCNJ2 accounted for all ATS patients (Table 3). Three SCN4A missense mutations were novel: the Arg669Gly mutation was found in a patient with HypoPP, a different missense mutation at the same codon (Arg669His) has been described previously in patients with HypoPP [17]. The Phe1419Ser mutation cosegregated with the disease in a father and son affected with HyperPP, and the $\operatorname{Arg} 1463$ His was identified in a sporadic patient with PMC; amino acid Arg is evolutionary highly conserved at this position.

\subsection{Genetic diagnoses and referrals}

The majority of genetic diagnoses of SMC were established in the DNA diagnostic laboratory of the academic medical center of Leiden (92\%). Nijmegen and Amsterdam both genetically diagnosed $4 \%$ of the Dutch SMC population. One SMC patient was genetically diagnosed in Maastricht. Eightysix percent of referrals for genetic testing of SMC patients in the Netherlands came from academic medical centers. The remaining $14 \%$ came from non-academic hospitals.

\section{Discussion}

Our nationwide study provides minimum point prevalence rates on genetically-defined SMC patients in the Netherlands, with underlying mutation spectrum and patient demographic characteristics. The calculated minimum point prevalence rates of 2.38/100.000 for the whole group of SMC, 1.70/100.000 for NDM and $0.69 / 100.000$ for PP, confirm their rare disease status (prevalence of <50/100.000) [18] in the Netherlands. The minimum point prevalence rate of SMC in the Netherlands $(2.38 / 100.000)$ is twice as high as the previously reported minimum point prevalence rate of $1.12 / 100.000$ in the UK. The UK study was, previous to our study, the only reliable nationwide estimate on the minimum point prevalence of genetically-defined SMC [7]. Some results show an overlap between the two studies: frequency distributions of disease groups NDM and PP (resp. 71\% and 29\% (NL) versus resp. 
Table 3

Frequency of individual mutations with sodium, calcium and potassium channelopathies within the group of patients with skeletal muscle channelopathies in the Netherlands.

\begin{tabular}{|c|c|c|}
\hline & Patients, N & Pedigrees, $\mathrm{N}$ \\
\hline \multicolumn{3}{|l|}{ PMC, SCM } \\
\hline \multicolumn{3}{|c|}{$S C N 4 A$ mutations } \\
\hline Arg225Trp & 1 & 1 \\
\hline Leu250Pro & 10 & 3 \\
\hline Val445Met & 9 & 4 \\
\hline Glu452Lys & 1 & 1 \\
\hline Arg675Trp & 3 & 2 \\
\hline Leu689Phe & 1 & 1 \\
\hline Val781Ile & 5 & 3 \\
\hline Pro1158Ser & 11 & 5 \\
\hline Ile1160Val & 1 & 1 \\
\hline Val1293Ile & 1 & 1 \\
\hline Gly1306Ala & 21 & 9 \\
\hline Gly1306Glu & 3 & 3 \\
\hline Gly1306Val & 54 & 27 \\
\hline Thr1313Met & 10 & 8 \\
\hline Leu1433Phe & 2 & 1 \\
\hline Arg1448Cys & 5 & 3 \\
\hline Arg1448His & 11 & 10 \\
\hline Val1458Phe & 13 & 2 \\
\hline Ile1455Thr & 1 & 1 \\
\hline Arg1463His & 1 & 1 \\
\hline Val1589Met & 3 & 2 \\
\hline \multicolumn{3}{|l|}{ НуроРР } \\
\hline \multicolumn{3}{|c|}{$C A C N A 1 S$ mutations } \\
\hline Arg489His & 3 & 1 \\
\hline Arg528His & 60 & 14 \\
\hline Arg1239His & 17 & 11 \\
\hline \multicolumn{3}{|c|}{$S C N 4 A$ mutations } \\
\hline Arg672His & 4 & 3 \\
\hline Arg1132Gln & 2 & 2 \\
\hline Arg1135His & 3 & 3 \\
\hline Arg669Gly & 1 & 1 \\
\hline \multicolumn{3}{|l|}{ НyperPP } \\
\hline \multicolumn{3}{|c|}{$S C N 4 A$ mutations } \\
\hline Thr704Met & 1 & 1 \\
\hline Met1592Val & 7 & 5 \\
\hline Phe1419Ser & 2 & 1 \\
\hline \multicolumn{3}{|l|}{ ATS } \\
\hline \multicolumn{3}{|c|}{ KCNJ2 mutations } \\
\hline Arg67Gln & 1 & 1 \\
\hline Thr75Arg & 1 & 1 \\
\hline Arg218Pro & 4 & 1 \\
\hline Arg218Trp & 6 & 2 \\
\hline Ile273Thr & 5 & 1 \\
\hline
\end{tabular}

Novel mutations are indicated in bold.

Abbreviations: $\mathrm{SCM}=$ sodium channel myotonia; $\mathrm{PMC}=$ paramyotonia congenita; HypoPP = hypokalemic periodic paralysis, HyperPP = hyperkalemic periodic paralysis; ATS = Andersen-Tawil syndrome; $S C N 4 A$ = voltage-gated skeletal muscle sodium channel gene; $C A C N A 1 S$ = voltage-gated skeletal muscle calcium channel gene; $K C N J 2$ = voltage-gated skeletal muscle potassium channel gene; $\mathrm{N}=$ number.

$67.5 \%$ and $32.5 \%(\mathrm{UK}))$, the relatively young SMC patient mean age (38 y (NL) versus $45 \mathrm{y}(\mathrm{UK}))$, and comparable mutation spectra; therefore we believe that these characteristics cannot account for the difference in prevalence rate. We used the available genetic information from the four genetic diagnostic centers in the Netherlands and traced back comprehensive demographic information, whereas in the UK, a single rare disease expert center served as the only clinical and genetic testing site. Since both studies share a service-based epidemiological design in which only individuals seeking medical attention were included, we do not believe that referral bias explains the difference in prevalence rates between the countries. The minimum point prevalence in the UK may be partly underestimated by the extra dimension of a geographical barrier (larger distances) in the UK, which may, in comparison to the Netherlands, lead to a relatively lower rate of referrals or visits to a single rare disease (diagnostic) center. In both studies, the real prevalence of SMC is probably much higher due to incomplete case ascertainment of mildly affected patients not seeking medical attention. Although not specifically tested for in this study, the presence of a strong founder effect (due to a combination of international migration and regional and religious endogamy) of SMC mutations in the Netherlands is suspected based upon the evidence of such an effect in many other genetic disorders [19]. The previously reported founder mutations in CLCN1 causing MC in northern Finland (Phe413Cys and Arg894*) are among the most common recessive CLCN1 mutations in the Netherlands, which supports this hypothesis. The most common dominant CACNA1S mutations (Arg528His and Arg1239His) causing HypoPP in the Netherlands and the UK showed no founder effect in 16 Caucasian HypoPP families in a previous study in 1995 [20]. Prevalence studies from the pre-genetic era conducted in parts of Scandinavia report high prevalence rates up till 9.0/100.000 for MC (Northern Norway), 1.1/100.000 for PMC (Western Sweden) and 1.3/100.000 for HypoPP (Denmark) [21-23]. The mutation-spectrum of SMC patients in the Netherlands is comparable with the reported mutationspectrum of SMC patients in the UK on different aspects: a limited number of mutations account for a large proportion of cases for all disease subtypes, especially in PP, and, apart from MC, all other disease subtypes are caused by missense mutations only. Controversially, some of the more common SMC mutations in the Netherlands are non-prevalent in the UK (such as the Leu250Pro and the Pro1158Ser mutation in SCN4A, the Arg489His in CACNA1S and the Ile273Thr in $K C N J 2$ ) and other more common mutations in the UK are non-prevalent in the Netherlands (the Gly230Glu mutation in CLCN1, the Leu1436Pro and the Arg675Gly in SCN4A, and the Arg82Gln in $K C N J 2$ ). Moreover, the majority of Dutch patients with CLCN1 mutations are from recessive pedigrees. Most patients are compound heterozygous and a smaller number are homozygous for CLCN1 mutations. We found a dominant inheritance pattern in only four families as observed in earlier studies of Dutch patients with chloride channelopathies [4]. Since the clinical phenotype and mutation analysis matched the diagnosis of dominant myotonia congenita in these families (with generalized myotonia, often in absence of transient paresis), we did not perform ancillary analysis for co-occurrence of myotonic dystrophy type 2 or a dominant SCN4A mutation as disease-modifiers [24,25]. The main 
shortcoming of our study is that we were unable to definitely confirm the presence of a SMC-phenotype for every individual included in the prevalence estimation due to the anonymous set-up of our study. Detailed clinical and electrophysiological information were available for around $50 \%$ of SMC patients, namely those patients who were primarily treated by a physician from our study team. Most genetic referrals $(86 \%)$ came from academic neuromuscular neurologists who specifically asked for single or in tandem genetic screening of genes associated with myotonia or periodic paralysis, after phenotypical characterization using national guidelines on clinical and electrophysiological diagnosis of SMC. This limits the possibility of wrongful inclusion of genetically-defined SMC patients in our cohort. Since we did not sequence the entire CACNA1S gene, and mutations have recently been described in other exons than we tested for [26], we cannot exclude a small underestimation in the prevalence of HypoPP. A strength of our study is the homogeneity of our study population accomplished by inclusion of only genetically-determined SMC patients in combination with the nationwide accessibility of genetic and diagnostic centers in the Netherlands. In conclusion, our results confirm the rare disease status of SMC in the Netherlands, while the reported mutation spectrum can optimize the clinical diagnostic process and allow for international collaboration and fast recruitment in future therapeutic trials.

\section{Appendix: Supplementary material}

Supplementary data to this article can be found online at doi:10.1016/j.nmd.2018.03.006.

\section{References}

[1] Raja Rayan DL, Hanna MG. Skeletal muscle channelopathies: nondystrophic myotonias and periodic paralysis. Curr Opin Neurol 2010;23:466-76.

[2] Statland JM, Barohn RJ. Muscle channelopathies: the nondystrophic myotonias and periodic paralyses. Continuum (N Y) 2013;19(6 Muscle Disease):1598-614.

[3] Trip J, Drost G, Ginjaar HB, Nieman FH, van der Kooi AJ, de Visser M, et al. Redefining the clinical phenotypes of non-dystrophic myotonic syndromes. J Neurol Neurosurg Psychiatry 2009;80:647-52.

[4] Trip J, Drost G, Verbove DJ, van der Kooi AJ, Kuks JB, Notermans NC, et al. In tandem analysis of CLCN1 and SCN4A greatly enhances mutation detection in families with non-dystrophic myotonia. Eur J Hum Genet 2008;16:921-9.

[5] Tawil R, Ptacek LJ, Pavlakis SG, DeVivo DC, Penn AS, Ozdemir C, et al. Andersen's syndrome: potassium-sensitive periodic paralysis, ventricular ectopy, and dysmorphic features. Ann Neurol 1994;35:326-30.

[6] Venance SL, Cannon SC, Fialho D, Fontaine B, Hanna MG, Ptacek LJ, et al. The primary periodic paralyses: diagnosis, pathogenesis and treatment. Brain 2006;129(Pt 1):8-17.

[7] Horga A, Raja Rayan DL, Matthews E, Sud R, Fialho D, Durran SC, et al. Prevalence study of genetically defined skeletal muscle channelopathies in England. Neurology 2013;80:1472-5.
[8] Boerman RH, Ophoff RA, Links TP, van Eijk R, Sandkuijl LA, Elbaz A, et al. Mutation in DHP receptor alpha 1 subunit (CACLN1A3) gene in a Dutch family with hypokalaemic periodic paralysis. J Med Genet 1995;32:44-7.

[9] Bokenkamp R, Wilde AA, Schalij MJ, Blom NA. Flecainide for recurrent malignant ventricular arrhythmias in two siblings with Andersen-Tawil syndrome. Heart Rhythm 2007;4:508-11.

[10] Schoonderwoerd BA, Wiesfeld AC, Wilde AA, van den Heuvel F, Van Tintelen JP, van den Berg MP, et al. A family with Andersen-Tawil syndrome and dilated cardiomyopathy. Heart Rhythm 2006;3:1346-50.

[11] Davies NP, Imbrici P, Fialho D, Herd C, Bilsland LG, Weber A, et al. Andersen-Tawil syndrome: new potassium channel mutations and possible phenotypic variation. Neurology 2005;65:1083-9.

[12] Matthews E, Labrum R, Sweeney MG, Sud R, Haworth A, Chinnery PF, et al. Voltage sensor charge loss accounts for most cases of hypokalemic periodic paralysis. Neurology 2009;72:1544-7.

[13] The municipal personal records database of the Dutch Government; 2015. Available from: https://www.government.nl/topics/personal-data/ personal-records-database-brp. [Accessed 1 January 2005].

[14] Schoenberg BS. Calculating confidence intervals for rates and ratios; simplified method utilizing tabular values based on the Poisson distribution. Neuroepidemiology 1983;2:257-65.

[15] Portaro S, Altamura C, Licata N, Camerino GM, Imbrici P, Musumeci O, et al. Clinical, molecular, and functional characterization of CLCN1 mutations in three families with recessive myotonia congenita. Neuromolecular Med 2015;17:285-96.

[16] Lehmann-Horn F, Jurkat-Rott K. Voltage-gated ion channels and hereditary disease. Physiol Rev 1999;79:1317-72.

[17] Bulman DE, Scoggan KA, van Oene MD, Nicolle MW, Hahn AF, Tollar LL, et al. A novel sodium channel mutation in a family with hypokalemic periodic paralysis. Neurology 1999;53:1932-6.

[18] Rodwell C, Aymé S, editors. 2014 Report on the state of the art of rare disease activities in Europe. 2014. Available from: http://www.eucerd.eu/ upload/file/Reports/2014ReportStateofArtRDActivities.pdf. [Accessed 1 December 2006].

[19] Zeegers MP, van Poppel F, Vlietinck R, Spruijt L, Ostrer H. Founder mutations among the Dutch. Eur J Hum Genet 2004;12:591-600.

[20] Elbaz A, Vale-Santos J, Jurkat-Rott K, Lapie P, Ophoff RA, Bady B, et al. Hypokalemic periodic paralysis and the dihydropyridine receptor (CACNL1A3): genotype/phenotype correlations for two predominant mutations and evidence for the absence of a founder effect in 16 Caucasian families. Am J Hum Genet 1995;56:374-80.

[21] Darin N, Tulinius M. Neuromuscular disorders in childhood: a descriptive epidemiological study from western Sweden. Neuromuscul Disord 2000;10:1-9.

[22] Johnsen T. Familial periodic paralysis with hypokalaemia. Experimental and clinical investigations. Dan Med Bull 1981;28:1-27.

[23] Sun C, Tranebjaerg L, Torbergsen T, Holmgren G, Van Ghelue M. Spectrum of CLCN1 mutations in patients with myotonia congenita in Northern Scandinavia. Eur J Hum Genet 2001;9:903-9.

[24] Ursu SF, Alekov A, Mao NH, Jurkat-Rott K. ClC1 chloride channel in myotonic dystrophy type 2 and $\mathrm{ClCl}$ splicing in vitro. Acta Myol 2012;31:144-53.

[25] Furby A, Vicart S, Camdessanche JP, Fournier E, Chabrier S, Lagrue E, et al. Heterozygous CLCN1 mutations can modulate phenotype in sodium channel myotonia. Neuromuscul Disord 2014;24:953-9.

[26] Li FF, Li QQ, Tan ZX, Zhang SY, Liu J, Zhao EY, et al. A novel mutation in CACNA1S gene associated with hypokalemic periodic paralysis which has a gender difference in the penetrance. J Mol Neurosci 2012;46:378-83. 